\title{
Controlando y regulando el cuerpo, la sexualidad y la maternidad de las mujeres centroamericanas (siglo XIX e inicios del siglo XX) ${ }^{1}$
}

\author{
Eugenia Rodríguez Sáenz²
}

Recepción: 12 de mayo de 2014 / Aprobación: 17 de junio de 2014

\section{Resumen}

Este artículo tiene como principal objetivo analizar el impacto de las reformas liberales sobre las legislaciones que regularon, controlaron y civilizaron el cuerpo y la sexualidad de las mujeres en América Central, en particular de las mujeres casadas, durante el siglo XIX y las primeras décadas del siglo XX. Aunque entre las reformas legales que se introdujeron en el siglo XIX resaltan el matrimonio, la separación y el divorcio civil, el principal foco será el análisis de otras reformas importantes que redefinieron el control y la regulación del cuerpo, la sexualidad y la maternidad de las mujeres casadas. Entre estas reformas, cabe mencionar: a) el matrimonio como contrato civil; b) la eliminación de la potestad marital; c) la regulación y control de la sexualidad y de la maternidad; y d) el ejercicio de la patria potestad compartida. Las principales fuentes en que se basó este trabajo son los diversos códigos civiles y otras fuentes complementarias, como las legislaciones y las discusiones disponibles de los países de América Central.

\section{Palabras clave}

Mujeres casadas; cuerpo; sexualidad; maternidad; Centroamérica; siglo XIX; inicios del XX

\section{Abstract}

The main objective of this article is to analyze the impact of liberal reforms over the laws that regulated, controled and civilized the body and sexuality of Central American women, married women in particular, during the nineteenth century and the begining of the twentieth century. Although among the legal reforms that were introduced in the nineteenth century highlighten civil marriage, separation and divorce, the main focus of this article will be other important reforms that contributed to redefine the control and regulation of the body, sexuality and maternity of married women.

$1 \quad$ Este artículo constituye un aporte parcial de un proyecto más amplio sobre los derechos civiles de las mujeres centroamericanas durante el siglo XIX e inicios del siglo XX, financiado por la Vicerrectoría de Investigación y auspiciado por la Escuela de Historia y el Centro de Investigación en Identidad y Cultura Latinoamericanas (CIICLA) de la Universidad de Costa Rica (UCR).

2 Costarricense. Doctora en Historia por la Indiana University, Bloomington, Estados Unidos. Catedrática de la Escuela de Historia, Investigadora y Coordinadora del Programa Géneros e Identidades en América Latina del CIICLA, UCR. Correo electrónico: eurosa61@gmail.com 
Among these reforms can be mentioned: a) the marriage as a civil contract; b) the elimination of marital potesty; c) the control and regulation of sexuality and maternity; and d) the exercise of shared "patria potestad". The main sources of this research are the civil codes and other complementary sources, such as legislations and discussions available about Central American countries.

\section{Key words}

Marrid women; body; sexuality; maternity; Central America; nineteenth century; twentieth century

\section{Resumo}

Este artigo tem como principal objetivo analisar o impacto das reformas liberais sobre as legislações que regularam, controlaram e civilizaram o corpo e a sexualidade das mulheres na América Central, especialmente das mulheres casadas, durante 0 século XIX e as primeiras décadas do século XX. Mesmo entre as reformas legais que foram introduzidas no século XIX destacam o casamento, a separação e o divórcio civil, o principal foco será a análise de outras reformas importantes que redefiniram o controle e a regulação do corpo, a sexualidade e a maternidade das mulheres casadas. Entre estas reformas, cabe mencionar: a) o casamento como contrato civil; b) a eliminação do poder civil; c) a regulação e controle da sexualidade e da maternidade; e d) o exercício da pátria poder compartilhada. As principais fontes em que este trabalho se baseia são os diversos códigos civis, e outras fontes complementares, como as legislações e as discussões disponíveis dos países de América Central.

\section{Palavras chave}

Mulheres casadas; corpo; sexualidade; maternidade; Centro-América; século XIX; inícios do XX

\section{Introducción}

I principal objetivo de este artículo es analizar el impacto que tuvieron las reformas liberales sobre las legislaciones que regularon, controlaron y civilizaron el cuerpo y la sexualidad de las mujeres en América Central, en particular de las mujeres casadas, durante el siglo XIX y las primeras décadas del siglo XX. En este sentido, Silvia Arrom apunta que:

La ley ofrece un marco esencial para la comprensión de la vida de las mujeres. Si bien el sistema legal [...] distinguía a las personas con base en muchos factores [...], el sexo atravesaba todas [las] categorías legales. Por eso, la distinta situación jurídica de las mujeres es un fuerte argumento para estudiarlas como grupo separado [...], [y a la vez] distinguir entre las leyes que se aplicaban a todas las mujeres y las que solo se aplicaban a las esposas. La ley española concedía considerablemente más derechos a las mujeres 
solteras y viudas que a las casadas, aunque menos que a los hombres de equivalente estado civil (Arrom, 1988, 70 y 72).

En efecto, la implementación de las reformas liberales durante el siglo XIX y el desarrollo e institucionalización de diversas instituciones represivas, punitivas de la moral sexual y doméstica, se expresó en particular en el control, la regulación y criminalización de los cuerpos y la sexualidad de las mujeres, y la represión de aquellas conductas que eran consideradas transgresoras del "orden" patriarcal y heterosexual.

Aunque entre las reformas legales que se introdujeron en el siglo XIX resaltan el matrimonio, la separación y el divorcio civil, este trabajo se centrará en el análisis de otras reformas importantes que redefinieron el control y la regulación del cuerpo, la sexualidad y la maternidad de las mujeres casadas. Entre estas reformas, cabe mencionar: a) el matrimonio como contrato civil; b) la eliminación de la potestad marital; c) la regulación y control de la sexualidad y de la maternidad; y d) el ejercicio de la patria potestad compartida.

El principal argumento es que estas reformas, sin duda, marcaron un hito porque debilitaron tanto como fortalecieron los derechos civiles de las mujeres, y más que "modernizar", contribuyeron a la vez a redefinir las relaciones y las identidades de género, y a reforzarlas bajo los mandatos del "orden" patriarcal y heterosexual. Es decir, la construcción identitaria de la mujer como esposa y madre recluida en el ámbito doméstico, sumisa, dependiente y obediente y dedicada a la crianza y educación de los hijos. Además, la construcción identitaria del hombre como jefe del hogar y principal proveedor, trabajador y sin vicios.

Las investigaciones sobre historia de las mujeres en América Central, se han concentrado en la temática de los derechos políticos y, particularmente, en el estudio sobre el sufragio femenino y los movimientos feministas durante la primera mitad del siglo XX (Rodríguez, 2002, 2005a, 2014). Aunque para América Latina y en particular para América Central hay algunos trabajos realizados, estos se concentran en el período del siglo XIX o el período posterior a la década de 1970. Entre estos estudios cabe mencionar los de Silvia Arrom (1985 y 1988) y de Ana Lidia García (2006) sobre la legislación de familia y las mujeres mexicanas durante el siglo XIX, y el de la que esto escribe sobre el divorcio y la violencia de pareja en Costa Rica en el período de 1800-1950. También se debe destacar el artículo pionero de Alda Facio (1989) sobre la igualdad de género y las relaciones familiares en la legislación centroamericana, con énfasis en la década de 1980.

También destacan el libro y los artículos recientes de Carmen Diana Deere y Magdalena León (2000, 2005, 2006), sobre las mujeres latinoamericanas y su acceso a la tierra durante los siglos XIX y XX, y el divorcio y el matrimonio civil en América Latina en el siglo XIX. A esto hay que agregar, algunos estudios en los cuales se mencionan varias de las principales tendencias en las condiciones y 
los derechos civiles de las mujeres en Costa Rica durante el siglo XIX y la primera mitad del siglo XX (Rodríguez, 2001, 2005b, 2006 y 2008).

Para el período reciente, también cabe citar algunos trabajos que compilan diversas legislaciones sobre los derechos socio-políticos de las mujeres costarricenses (Salvatierra et al., 1978-1980; INAMU, 2009), y los estudios que enfatizan el análisis de los derechos políticos y de los movimientos de mujeres, y feministas en Centroamérica durante las décadas de 1980 y 1990 (Aguilar et al., 1997; García, 1999). Conviene indicar que en estos trabajos también predomina un enfoque presentista y ahistórico, por lo que carecen de una perspectiva histórica que nos permita contextualizar más adecuadamente cuáles han sido las características de los procesos previos de reforma de los derechos de las mujeres durante el siglo XIX y primeras décadas del siglo XX.

Este trabajo forma parte de una investigación más amplia sobre los derechos civiles de las mujeres centroamericanas. Las principales fuentes en que se basó son los diversos códigos civiles (13 en total), y otras fuentes complementarias, como la bibliografía, las legislaciones y las discusiones disponibles de los países de América Central (véase Cuadro 1)3. Por lo tanto, este artículo es un punto de partida para la realización de investigaciones futuras más profundas, que nos permitan comprender mejor el impacto que tuvieron dichas reformas en las identidades y las relaciones de género ${ }^{4}$.

Para los efectos de este artículo, se analizará el impacto que tuvieron las reformas liberales sobre las legislaciones que regularon, controlaron y civilizaron el cuerpo y la sexualidad de las mujeres casadas en América Central, durante el siglo XIX y las primeras décadas del siglo XX, iniciando con una breve contextualización sobre el desarrollo de las reformas liberales. Entre las reformas que se analizarán, destacan: 1) la reconceptualización del matrimonio de un contrato sagrado e indisoluble a un contrato civil, secular y temporal; 2) la eliminación de la potestad marital; 3) las legislaciones que controlaron y regularon la sexualidad y la maternidad; y 4) la patria potestad compartida.

\section{El contexto de las reformas liberales}

La contextualización histórica es importante para poder comprender mejor el impacto que tuvieron las reformas liberales, en la evolución de los derechos y las condiciones de las mujeres centroamericanas, entre el siglo XIX y las primeras décadas del siglo XX.

3 Mediante un largo proceso, en el marco de varios proyectos de investigación realizados por la suscrita (1992-2012), fue posible recopilar estas fuentes en distintas bibliotecas de Costa Rica (Biblioteca Nacional, Biblioteca de la Corte Suprema de Justicia y Biblioteca de la Facultad de Derecho de la Universidad de Costa Rica); y de los Estados Unidos (entre otras, The Library of Congress, Indiana University, Tulane University y University of California at Berkeley).

4 En general, en los países centroamericanos hay pocas investigaciones históricas al respecto, para el caso de Costa Rica se dispone de una mayor producción, véase al respecto: Rodríguez, 2002, 2005a, 2014. 
Cuadro 1. Códigos civiles de América Central (siglos XIX y XX)

\begin{tabular}{|c|c|c|}
\hline País & Códigos civiles siglo XIX & Códigos civiles siglo XX \\
\hline Costa Rica & 1841,1888 & 1974 \\
\hline El Salvador & 1860 & ----- \\
\hline Guatemala & 1877 & 1926,1933 \\
\hline Honduras & 1880,1898 & 1906 \\
\hline Nicaragua & 1871 & 1904 \\
\hline Panamá $^{2}$ & ----- & 1917 \\
\hline
\end{tabular}

Notas:

1. Se refiere a: Costa Rica, Código de Familia (San José, Tipografía Nacional, 1974).

2. Panamá se independizó de Colombia por lo que antes del Código Civil de Panamá de 1917 estuvo vigente el Código Civil de Colombia (Código Civil de la República de Panamá, 1960, 1).

Fuentes: María G. Leret de Matheus, La mujer: una incapaz como el demente y el niño. (Según las leyes latinoamericanas), México, Costa-Amic Editor, 1975, pp. 51, 112, 131, 194 y 276; Carmen Diana Deere y Magdalena León. El liberalismo y los derechos de propiedad de las mujeres casadas en el siglo XIX en América Latina. En Magdalena León y Eugenia Rodríguez. (Eds.). ¿Ruptura de la inequidad? Propiedad y género en la América Latina de/ siglo XIX (Bogotá, Siglo del Hombre Editores, 2005), 40-41, 47-49, 71 y 92-103; Carmen Diana Deere y Magdalena León. Matrimonio y divorcio civil en América Latina durante el siglo XIX. En XI Cátedra Anual de Historia Ernesto Restrepo Tirado. (Ed.). Mujer, nación, identidad y ciudadanía: siglos XIX y XX (Bogotá, MinCultura Memorias, 2006), 78-101; Eugenia Rodríguez, Las esposas y sus derechos de acceso a la propiedad en Costa Rica durante el siglo XIX. En Magdalena León y Eugenia Rodríguez. (Eds.). ¿Ruptura de la inequidad? Propiedad y género en la América Latina del siglo XIX (Bogotá, Siglo del Hombre Editores, 2005a), 183-232. Costa Rica: Código General de Costa Rica (1841) (Nueva York: Imprenta de Wynkoop, Hallenbeck y Thomas, 1858); Código Civil 1888 (San José: Tipografía Nacional, 2a ed., 1910). El Salvador: Código Civil de la República del Salvador en Centroamérica (Nueva York: Imprenta de Eduardo C. Jenkins, 26 Calle de Frankfurt, 1860); Código Civil de la República del Salvador. Quinta edición en la que se han intercalado todas las reformas posteriores hasta el año de mil novecientos doce. Editores y propietarios Dutriz Hermanos (San Salvador, El Salvador: Tipografía "La Unión", 1912). El Salvador no tiene Código Civil en el siglo XX, pero sí diversas ediciones revisadas en: 1880, 1893, 1904, 1912 y 1926 (Véase: Napoleón Rodríguez. El proceso histórico del Código Civil, Código Civil de la República del Salvador en Centroamérica. (Estudios y conferencias sobre el Código Civil de 1860), $2^{a}$ ed. (San Salvador, El Salvador, C.A.: Editorial Universitaria "José B. Cisneros", 13 de julio, 1960, 57). Guatemala: Código Civil de la República de Guatemala, 1877 (Ciudad de Guatemala: Imprenta El Progreso, 1877); Código Civil de la República de Guatemala, 1926 (Ciudad de Guatemala: Tipografía Nacional, Guatemala, C.A., 1927); Código Civil de la República de Guatemala, 1937 (Guatemala: Tipografía Nacional, 1937). Honduras: Código Civil de la República de Honduras 1880 (Tegucigalpa: Tipografía Nacional, Calle de la Estación, 1880); Código Civil de 1898 (Tegucigalpa: Tipografía Nacional, Tercera Av. Este, No. 42, 1898); Código Civil 1906 (Tegucigalpa, Honduras: Tipografía Nacional, 1906). Nicaragua: Código Civil de la República de Nicaragua aprobado 25 enero 1867 (Managua, Nicaragua: Imprenta de El Centro-Americano, 1871, vigente a partir de 1871); José Santos Zelaya y Fernando Abaunza, Código Civil de la República de Nicaragua elaborado de orden del Señor Presidente General Don J. Santos Zelaya y su Ministro de Justicia Don Fernando Abaunza, por la Comisión Oficial de Códigos compuesta de los Abogados Bruno H. Buitrago, José Francisco Aguilar y Francisco Paniagua Prado (Managua, Nicaragua: Tipografía Nacional, 1903, vigente a partir de 1904); Código Civil de la República de Nicaragua. Revisado definitivamente por la Comisión Legislativa compuesta de los Diputados Doctor don Leonardo Rodríguez y don Santiago López y de los Abogados Bruno H. Buitrago, J. F. Aguilar y F. Paniagua Prado. Tercera Edición Oficial. Anotada y concordada por los doctores Carlos A. Morales, Joaquín Cuadra Zavala y Mariano Argüello (Managua, Nicaragua: Casa Editorial Carlos Heuberger y Co., $3^{a}$ ed. oficial, 1931). Panamá: Panamá no tiene Código Civil en el siglo XIX, debido a que se independizó de Colombia en 1903, por lo que estuvo vigente el Código Civil Colombiano (Código Civil de la República de Panamá, 1960: 1). Código Civil de la República de Panamá. Edición conmemorativa del XXV aniversario (Panamá: Universidad de Panamá, 1960). Esta edición es una versión revisada del Código Civil de 1917, el cual estuvo vigentea partir de noviembre de 1917; Alfonso Correa García, Código Civil de la República de Panamá. Anotaciones (Panamá: Imprenta Nacional, 1927). 
En efecto, al independizarse los países centroamericanos de España en 1821, se inició un complejo proceso de transición de la era colonial al período de construcción del Estado-nación, acompañado por una gran inestabilidad socio-política generada por la Federación Centroamericana (1824-1839) y las luchas entre liberales y conservadores por acceder, y mantenerse en el poder.

Sin embargo, a diferencia del resto de los países centroamericanos, en Costa Rica el proyecto político liberal y las reformas liberales sí lograron consolidarse en forma temprana, gradual y exitosa durante el siglo XIX e inicios del siglo XX (Pérez, 1989, 79-106; Mahoney, 2002, 133-166). Se debe tener en consideración, que el caso de Panamá tiene la especificidad de que pasó por otro proceso al independizarse de Colombia en 1903, la primera constitución política se aprobó recién en 1904, y se incluyeron las reformas a la legislación de familia en el primer Código Civil, que empezó a regir en $1917^{5}$.

Durante el siglo XIX e inicios del siglo XX, diversos gobiernos de orientación liberal fueron ejecutando paulatinamente una serie de reformas a la legislación familiar, junto con otras reformas anticlericales. Estas reformas buscaban secularizar la sociedad, consolidar un modelo hegemónico liberal y escindir, y redefinir con claridad los campos de acción socio-política de la Iglesia y del Estado, todo con el propósito de delimitar el poder de la Iglesia (Molina y Palmer, 1998, 54-56). En este proceso, también adquiere gran relevancia la discusión sobre la regulación de la moral doméstica y las funciones sociales del matrimonio, la familia y las mujeres, ya que estas se consideraban las principales pilares garantes del orden, el progreso, la armonía, la educación y la civilización de los futuros ciudadanos.

Sin duda, las reformas sobre la legislación de familia, en particular el matrimonio, la separación y el divorcio civil, junto con otras reformas anticlericales en América Central, propiciaron un clima de creciente y abierto enfrentamiento socio-político entre la Iglesia católica, los sectores conservadores y liberales, y el Estado, cuyo balance de fuerzas fue uno de los factores clave que explica cuándo, cómo y por qué se vieron obstaculizadas, postergadas o aprobadas dichas reformas (Rodríguez, 2006, 45-68).

En el caso de Costa Rica, en particular, las reformas anticlericales de 1884 y $1886^{6}$, permitieron a los liberales consolidar la secularización de diversos

5 Fábrega, 1969; Correa, 1927; Código Civil de la República de Panamá, ed. 1960. Esta edición de 1960 es una versión revisada del Código Civil de 1917, el cual estuvo vigente a partir de noviembre de 1917. Antes de este código estuvo vigente el Código Civil de Colombia (Código Civil de la República de Panamá, 1960, 1).

6 Las medidas anticlericales adoptadas en 1884 incluyeron: 1) la expulsión del Obispo Thiel y de la Compañía de Jesús por trastornar el orden público; 2) la secularización de los cementerios; 3) la prohibición de ingreso de órdenes monásticas al territorio nacional; 4) la derogación del Concordato; 5) la prohibición de colecta de limosna u otros trámites por parte del clero; 6) la prohibición de las procesiones, salvo las de Semana Santa, Corpus Christi y el Santo del lugar. La principal reforma de 1886 consistió en la secularización de la educación, la cual supuso la prohibición de incluir la educación religiosa en los programas de enseñanza aunada a la previa prohibición al clero de que 
servicios y ámbitos claves controlados anteriormente por la Iglesia, como los cementerios y la educación (1886), derogar el Concordato, eliminar una serie de privilegios y beneficios que la Iglesia recibía del Estado, y más tarde, crear el Registro Civil para controlar el registro de natalidad, nupcialidad y mortalidad.

Por lo tanto, se puede argumentar que al igual que en otras partes de América Latina, en los países centroamericanos las reformas liberales no implicaron rupturas drásticas con respecto a la época colonial, sino que introdujeron cambios graduales los cuales contribuyeron a redefinir y secularizar las funciones de la familia y el matrimonio, las relaciones de género y los derechos de las mujeres (Rodríguez, 2005, 192, 185). También, las reformas liberales tuvieron como resultado, por un lado, cambios progresistas de género o un avance hacia una igualdad formal ante la ley; y por otro, el mantenimiento -aunque mitigado- de las condiciones de desigualdad en los derechos reales de las mujeres, las cuales se materializan en las prácticas y procedimientos legales así como en los usos y costumbres (Deere y León 2000, 1, 45-82, 405; Deere y León, 2005, 30-31).

Es importante destacar que la introducción de las reformas liberales en los códigos civiles centroamericanos, se dio en un contexto en el cual adquiere gran importancia el debate sobre el papel de las mujeres en la sociedad; además, los sectores liberales muestran un creciente interés por desarrollar legislaciones que fortalecieran los derechos femeninos y por promover una serie de políticas sociales que mejoraran las condiciones sociales, morales y educativas de las mujeres.

Otro aspecto que es necesario resaltar, es que en estos debates en América Central no figuraron los movimientos obrero y femenino, ya que estos tuvieron su mayor ímpetu en un período posterior a dichas reformas: el movimiento obrero a partir de las primeras décadas del siglo XX, y el movimiento femenino a partir del decenio de 1920. En este artículo, lamentablemente, no nos será posible profundizar más en estos debates, ya que tal problemática rebasa los objetivos de este trabajo, y porque solo se dispone de estudios detallados para el caso costarricense (Rodríguez, 2006).

\section{Matrimonio, familia e identidades de género}

Para comprender el papel de algunas de estas normativas legales que redefinieron el control, regulación y sometimiento de las mujeres casadas bajo el dominio masculino es necesario empezar por la institución del matrimonio y la familia, que también se constituyen en los principales pilares sobre los cuales se reproducen las relaciones patriarcales.

Al igual que en otros de los países de América Latina, en los códigos civiles centroamericanos se normatiza y redefine el papel del matrimonio y de la

impartiera lecciones en los establecimientos educativos públicos (Vargas, 1991, 141, 145, 170-175). 
familia, entre el siglo XIX e inicios del siglo XX. Entre estas reformas destacan el matrimonio, la separación y el divorcio civil, a partir de las cuales el matrimonio se reconceptualizó de un contrato sagrado e indisoluble a un contrato secular y temporal, y los derechos de las mujeres a la vez se fortalecieron y debilitaron.

Excepto en el Código Civil de Panamá (1917), en los primeros códigos civiles de los países centroamericanos, la Iglesia católica mantuvo la autoridad para establecer los impedimentos y autorizar el matrimonio y la separación, al igual que en la legislación colonial. También, se mantuvo intacta la concepción de que el matrimonio era "perpetuo", un sacramento, de carácter indisoluble y por mutuo consentimiento, y que sus principales fines eran la fidelidad, la procreación y el mutuo auxilio?. Así, por ejemplo, se establecía en el Código Civil de Nicaragua de 1871, que:

Artículo 103. El matrimonio es un contrato solemne por el cual un hombre y una mujer se unen actual e indisolublemente, y por toda la vida, con el fin de vivir juntos, de procrear, y de auxiliarse mutuamente.

Artículo 104. Toca a la autoridad eclesiástica decidir sobre la validez del matrimonio que se trata de contraer o se ha contraído.

La ley civil reconoce como impedimentos para el matrimonio los que han sido declarados tales por la Iglesia Católica; y toca a la autoridad eclesiástica decidir sobre su existencia y conceder dispensa de ellos?.

Por otra parte, tales normativas reforzaron el modelo del matrimonio heterosexual y el carácter patriarcal de las identidades y de las relaciones de género. Así, las mujeres casadas quedaban en una posición subordinada y dependiente del esposo, sujeta al ámbito doméstico, y encargada tanto de la crianza como de la educación de los hijos y del cuidado de su marido. A los hombres, se les otorgaba el poder sobre su esposa e hijos, como jefe de la familia y principal proveedor. En este sentido, se establecía en el Código Civil de Guatemala de 1926, que:

Artículo 148.-Los cónyuges están obligados a guardarse fidelidad, a prestarse asistencia y mutuo auxilio.

El marido es el jefe y representante de la familia y en su defecto la mujer [...].

Artículo 150.-Los esposos están obligados a hacer vida en común y la mujer debe seguir a su marido [...]. 
Artículo 153.-La mujer tendrá el derecho y la obligación de dirigir los quehaceres del hogar. En la esfera de su acción doméstica, tendrá el derecho y el deber de cuidar los asuntos del marido. Los actos jurídicos que realice dentro de estos límites, se reputan autorizados por el marido, a no ser que de las circunstancias resulte claramente lo contrario ${ }^{9}$.

Destaca, además, que en ciertos códigos civiles la sujeción de la esposa incluía también el agregar (Guatemala) o adoptar el apellido del marido (El Salvador), prácticas socioculturales que todavía parecen mantenerse. En este sentido, en los códigos civiles guatemaltecos se ordenaba que la esposa agregara a su apellido el de su marido. Esta normativa, aparte de evidenciar cierto trasfondo social, sin duda implicaba que la mujer casada se convertía en objeto de pertenencia y sometida al dominio de su esposo. A este respecto se indicaba en el Código Civil de Guatemala de 1926, que:

Artículo 151.-Por el matrimonio la mujer agrega a su propio apellido el de su cónyuge, y conserva su nacionalidad, a menos que quiera adoptar la del marido ${ }^{10}$.

\section{La potestad marital: la esposa objeto y sujeto del dominio masculino}

Otra normativa tendiente a controlar y someter a las mujeres casadas bajo el dominio masculino, es la denominada potestad marital. Al igual que en la legislación colonial y eclesiástica en los primeros códigos civiles -excepto el de Panamá-, se mantuvo la normativa de la potestad marital sobre las esposas, la cual aseguraba el dominio de los maridos sobre su persona y bienes ${ }^{11}$.

En el Código Civil de Nicaragua 1871, se definía que "corresponde al varón la potestad marital que es el conjunto de derechos que las leyes le conceden sobre la persona y bienes de la mujer"12.

Al estar las esposas sometidas a la potestad marital, con excepción de su libertad para testar, el marido podía obligarla a habitar con él, a obedecerle y a seguirle a donde quiera que traslade su residencia. A la vez, el marido tenía la potestad para administrar todos sus bienes e ingresos, y ellas le debían solicitar autorización para comparecer a juicio o para dar, enajenar, hipotecar o adquirir algún bien. Por lo tanto, las mujeres al casarse pasaban de estar sujetas a la autoridad del padre a estar sujetas a la potestad marital, bajo la cual prácticamente perdían su derecho a decidir sobre sus bienes, lugar de

9 Código Civil de Guatemala 1926, Libro I, Tit. IV, Par. IV, Arts. 148-150 y 153.

10 Código Civil de Guatemala 1926, Libro I, Tit. IV, Par. IV, Art. 151.

11 Código Civil Guatemala 1877, Libro I, Arts. 153-156; Código Civil El Salvador 1860, Libro I, Arts. 134-135, 137-141, 147, 150, 153-154; Código Civil Honduras 1880, Libro I, Arts. 172-179; Código Civil Nicaragua 1871, Libro I, Arts. 133-137, 139-145, 150; Código General de Costa Rica 1841, Libro I, Arts. 53, 132-133, 135-136, 142.

12 Código Civil de Nicaragua 1871, Libro I, Art. 133. 
residencia, movilidad y ejercicio de alguna profesión. Por lo tanto, la potestad marital se inspiraba en la creencia, de que:

El matrimonio era un contrato dentro del cual las mujeres acordaban obedecer a sus esposos a cambio de protección [...]. La ley les daba a ellos el control de facto sobre los servicios y propiedades de sus esposas, y ultimadamente también sobre su persona (Abrams, 1999, 120-121).

Código Civil de Guatemala de 1877 establecía con respecto a la potestad marital lo siguiente:

150. El marido debe proteger a la mujer, y la mujer obedecer al marido.

151. La mujer está obligada a habitar con el marido y a seguirlo donde él tenga por conveniente residir [...].

153. La mujer no puede presentarse en juicio sin la autorización de su marido, pero no la necesita cuando es acusada en causa criminal, ni para demandar o defenderse en los pleitos con su marido.

154. La mujer no puede dar, enajenar, hipotecar, ni adquirir a título gratuito u oneroso, sin intervención del marido, o sin su consentimiento por escrito.

155. Puede no obstante, sin la autorización del marido:

10 Testar.

$2^{\circ}$ Suceder por testamento o ab intestato con beneficio de inventario.

156. La autorización del marido podrá ser suplida por el Juez con conocimiento de causa, cuando el marido se la negare sin justo motivo y de ello se siga perjuicio a la mujer ${ }^{13}$.

Además, al estar la esposa sujeta a la potestad marital, debía solicitar autorización de su marido para ejercer una profesión o industria. Así, el marido se aseguraba el control de la persona, la movilidad, los ingresos y el sometimiento de la esposa al ámbito doméstico, y de paso, reafirmar el poder masculino sobre la familia y como principal proveedor. A excepción de Costa Rica, esta legislación se mantuvo vigente en los primeros códigos civiles de Nicaragua (1871), Guatemala (1877), El Salvador (1860) y Honduras (1880) (véase Cuadro 2) ${ }^{14}$. En este sentido se indicaba en el Código Civil de Guatemala de 1877, que:

160. Si la mujer casada ejerce públicamente una profesión o industria cualquiera, como la Directora de Colegio, maestra de escuela, actriz, obstetriz, posadera, nodriza, se presume la autorización general del marido para todos los actos y contratos concernientes a su profesión o industria, mientras no intervenga reclamación o protesta de su marido notificada de antemano al público o especialmente al que contratare con la mujer.

161. La mujer casada, mercadera, está sujeta a las reglas especiales determinadas en el Código de comercio ${ }^{15}$.

13 Código Civil Guatemala 1877 (Libro I, Arts. 153-156).

14 Código Civil Guatemala 1877 (Libro I, Arts. 160-161; Código Civil El Salvador 1860, Libro I, Arts. 153154); Código Civil Honduras 1880 (Libro I, Arts. 191-192); Código Civil Nicaragua 1871 (Libro I, Arts. 153-154). 
Sin embargo, como se puede apreciar en el Cuadro 2, entre fines del siglo XIX e inicios del XX, se eliminó la potestad marital en los países de América Central. La base de esta reforma se inspira en el principio de la libertad civil individual, con la cual a las mujeres se les reconoció su capacidad jurídica en igualdad de condiciones que los hombres. Además, esta reforma, sin duda, implicó un avance particularmente importante en cuanto a los derechos de acceso de las mujeres casadas a la propiedad, al poder administrar sus bienes y propiedades independientemente, y sin el permiso de sus maridos (Deere y León, 2005, 51-52).

\begin{tabular}{|c|c|c|}
\hline Cuadro 2. Рote & MARITAL EN AMÉRIC/ & Central (siglos XIX y XX) \\
\hline País & Potestad marital $^{1}$ & Eliminación de la potestad marital ${ }^{2}$ \\
\hline Costa Rica & 1841 & 1888 \\
\hline El Salvador & 1860 & 1902 \\
\hline Nicaragua & 1871 & 1904 \\
\hline Honduras & $1880 / 1898$ & 1906 \\
\hline Panamá & ----- & 1917 \\
\hline Guatemala & 1877 & 1926 \\
\hline $\begin{array}{l}\text { Notas: } \\
\text { 1. Potestad marital: } \\
\text { Libro I, Arts. 134-135 } \\
\text { Código Civil Nicaragu } \\
\text { Libro I, Arts. 53, 132- } \\
\text { 2. Administración pro } \\
\text { podía hacer contrato } \\
\text { Código Civil de Guate } \\
\text { 189, ed. 1912); Códit } \\
\text { 1906 (Libro I, Art. 17 } \\
\text { Costa Rica de 1888 } \\
\text { de } 1917 \text { (Libro IV, Tit. }\end{array}$ & $\begin{array}{l}\text { go Civil Guatemala 1877, L } \\
\text { 37-141, 147, 150, 153-154 } \\
\text { 871, Libro I, Arts. 133-137, } \\
\text { 3, 135-136, 142. } \\
\text { de bienes/eliminación de la } \\
\text { entrar en juicios sin el perm } \\
\text { la de } 1926 \text { (Libro I, Art. } 166 \\
\text { Civil de Honduras de } 1898 \\
\text { d. 1997); Código Civil de N } \\
\text { o I, Art. 78); Panamá, Ley } \\
\text { Art. 1167). }\end{array}$ & $\begin{array}{l}\text { oro I, Arts. 153-156; Código Civil El Salvador 1860, } \\
\text { Código Civil Honduras 1880, Libro I, Arts. 172-179; } \\
\text { 139-145, 150; Código General de Costa Rica 1841, } \\
\text { ootestad marital: "se refiere a cuando la esposa } \\
\text { o del marido" (Deere y León, 2005a: 71).Véase: } \\
\text {; Código Civil de El Salvador de } 1860 \text { (Libro I, Art. } \\
\text { ibro I, Arts. 65-69); Código Civil de Honduras de } \\
\text { aragua de 1904 (Libro I, Art. 157); Código Civil de } \\
\text { /112/1914 (Arts. 3, 11, 13); Código Civil de Panamá }\end{array}$ \\
\hline $\begin{array}{l}\text { Fuentes: María G. Le } \\
\text { yes latinoamericanas } \\
\text { Magdalena León, El li } \\
\text { América Latina. En N } \\
\text { y género en la Améri } \\
\text { y 92-103; Carmen Di } \\
\text { el siglo XIX. En XI C } \\
\text { y ciudadanía: siglos } \\
\text { esposas y sus derec } \\
\text { León y Eugenia Rod } \\
\text { del siglo XIX (Bogotá }\end{array}$ & $\begin{array}{l}\text { de Matheus, La mujer: un } \\
\text { léxico, Costa-Amic Editor, } \\
\text { alismo y los derechos de } p \\
\text { dalena León y Eugenia Roc } \\
\text {-atina del siglo XIX (Bogotá } \\
\text { Deere y Magdalena León. N } \\
\text { dra Anual de Historia Erne } \\
\text { y XX (Bogotá, MinCultura } \\
\text { s de acceso a la propiedac } \\
\text { ez. (Eds.). ¿Ruptura de la ir } \\
\text { glo del Hombre Editores, } 2\end{array}$ & $\begin{array}{l}\text { incapaz como el demente y el niño. (Según las le- } \\
975,51,112,131,194 \text { y 276; Carmen Diana Deere y } \\
\text { opiedad de las mujeres casadas en el siglo XIX en } \\
\text { íguez. (Eds.). ¿Ruptura de la inequidad? Propiedad } \\
\text { Siglo del Hombre Editores, 2005), 40-41, 47-49, } 71 \\
\text { atrimonio y divorcio civil en América Latina durante } \\
\text { to Restrepo Tirado. (Ed.). Mujer, nación, identidad } \\
\text { hemorias, 2006), 78-101; Eugenia Rodríguez. Las } \\
\text { en Costa Rica durante el siglo XIX. En Magdalena } \\
\text { equidad? Propiedad y género en la América Latina } \\
\text { 05a), 183-232. }\end{array}$ \\
\hline
\end{tabular}

Según el Cuadro 2, Costa Rica fue el primer país de América Central en eliminar la potestad marital en 1888, mientras el resto de los países lo hicieron a inicios del siglo XX (entre 1902 y 1926). En este sentido, el artículo 78 del Código Civil de Costa Rica de 1888 determinaba que: 
Artículo 78. Es permitida la contratación entre los cónyuges, y la mujer no necesita autorización del marido, ni del juez para contratar ni para comparecer en juicio. Esta disposición se extiende a los matrimonios contraídos bajo la legislación anterior ${ }^{16}$.

Esta reforma que eliminaba la potestad marital, se dio en un contexto de gran debate en la Comisión Codificadora y el Colegio de Abogados de Costa Rica, los cuales la aprobaron en 1884 y estuvo vigente a partir de 1888. En este sentido, un autor desconocido afirmaba en el artículo "La sociedad conyugal y la separación de bienes", publicado en la revista El Foro el 5 de julio de 1884, que esta reforma fue aprobada por unanimidad por el Colegio de Abogados y no mermaba el papel del hombre como jefe de familia, ya que:

La mujer es capaz de administrar sus bienes y de enajenarlos debidamente, y la ley no la debe privar del ejercicio de esta capacidad [...]. El Colegio de Abogados no priva al marido de la calidad de jefe de familia, ni le arrebata la patria potestad sobre sus hijos. Se limita a que la mujer pueda administrar y enajenar lo que heredó de sus padres, lo que a ella sola se lega o se dona. Esta facultad continuará elevando su inteligencia y perfeccionando su educación. La reforma es tan importante que el Colegio de Abogados, a solicitud de su Presidente, el Señor Licenciado Volio, la aprobó por aclamación y batiendo palmas ${ }^{17}$.

Posteriormente, Alberto Brenes Córdoba afirmaba en un artículo publicado en 1888, que esta reforma que eliminaba la potestad marital se podía considerar un verdadero hito, ya que contribuyó a:

Establecer la igualdad entre los cónyuges [...]. Falsas opiniones acerca de la incapacidad de la mujer y de la autoridad marital dieron por resultado el que las antiguas legislaciones establecieran la preponderancia del marido. Más un concepto racional y justo ha venido en nuestro tiempo a destruir esas arraigadas preocupaciones y a colocar las cosas en su verdadero punto ${ }^{18}$.

Falta investigar más detalladamente esta problemática para establecer las razones de la especificidad costarricense, pero se debe indicar que, por la época en que esta reforma se aprobó, la matrícula de niñas en la escuela primaria había experimentado avances importantes, con una disminución significativa de la brecha que separaba a niños y niñas. También había habido un aumento de la inscripción de jóvenes en la enseñanza secundaria, proceso que se consolidaría a partir de 1888 con la fundación del Colegio Superior de Señoritas. Por último, hacia la década de 1880, la proporción de mujeres como maestras, igualmente, se había elevado, y en el decenio de 1890 dominarían ya esa ocupación docente (Molina y Palmer, 2004, 169-207; Muñoz, 2002; Palmer y Rojas, 2000, 57-102; Molina, 2000).

16 Código Civil de Costa Rica 1888 (Libro I, Art. 78).

17 El Foro, Tomo II, No. 28, 5/7/1884, 31.

18 El Foro, Tomo IV, No. 111, 2/12/1888, 124-125. 
No obstante, cabe mencionar que en las denuncias por violencia de pareja se evidencia que, actualmente, se encuentra bastante arraigada la representación de masculinidad hegemónica, en la cual el hombre debe mantener el control de la familia, los bienes, afectos y movilidad de su pareja, ejerciendo la violencia patrimonial, emocional y física (INAMU, 2009).

\section{Sexo antes y fuera del matrimonio: pecado, deshonra y delito}

Antes, durante y después del matrimonio, el cuerpo, la sexualidad y la maternidad de las mujeres eran objeto del domino patriarcal, pero un cambio importante es que también la sexualidad femenina fue objeto de creciente criminilización durante el siglo XIX. Aunque falta realizar muchos estudios para los países centroamericanos, se ha demostrado ampliamente en el caso costarricense, que con el proceso de codificación, la constitución de un aparato punitivo y de una red de tribunales civiles durante los siglos XIX y XX, se transitó de considerar pecado a delito el rapto, el abuso sexual y la violación, con penas de cárcel y de reclusión que incluso podían cubrir a la víctima. Además, la sospecha de deshonra por el "uso del cuerpo femenino" de sus "propiedades preciosas", implicaba y continúa implicando la "deshonra" de la familia y de la comunidad, por lo que era frecuente que una figura masculina se presentara para salvaguardarlo y exigir su restitución (Rodríguez, 1994, 2000, 2005c, 2006). De igual forma, cabe destacar que dentro de las políticas de salubrización y regulación de la moral sexual, se empezó a regular y perseguir el ejercicio de la prostitución femenina, desde mediados del siglo XIX (Marín, 2005, 2007).

En el caso específico de las reformas legales que implicaron cambios importantes sobre el control y la regulación del cuerpo, la sexualidad y la maternidad de las mujeres casadas, el análisis de las causales de divorcio civil también nos permite dar otras miradas. En términos generales en los códigos civiles centroamericanos de los siglos XIX e inicios del siglo XX, se incluían entre las principales doce causales de divorcio civil, las siguientes:

1) El adulterio de la mujer.

2) Preñez de la mujer por relaciones ilícitas.

3) El concubinato escandaloso del marido.

4) La sevicia y ofensas graves.

5) El atentado contra la vida del otro cónyuge.

6) El abandono voluntario y malicioso que uno de los cónyuges haga del otro.

7) La tentativa del marido de prostituir a su mujer; y la del marido o la mujer para corromper a sus hijos.

8) La negativa del marido de cumplir con la obligación de dar alimento a su mujer e hijos.

9) La negativa sin justificación de la mujer de seguir a su marido. 
10) El absoluto abandono en la mujer de los deberes de esposa y madre, y el absoluto abandono del marido en el cumplimiento de los deberes de esposo y padre.

11) Que el marido se encuentre sometido a la embriaguez habitual y escandalosa.

12) La condena de uno de los cónyuges a pena infamante ${ }^{19}$.

Entre estas causales destacan en particular la de adulterio y preñez de la esposa y el concubinato escandaloso del marido. Es importante enfatizar que la causal de preñez de la esposa solo era contemplada en el Código Civil de Honduras (1906) y el Código Civil de Nicaragua (1904 y 1931). No obstante, en la práctica, el hecho de que la esposa o compañera quedara embarazada de otra pareja, sin duda, implicaba aparte de ser objeto de deshonra y rechazo, con mucha frecuencia podía ser un motivo de separación y, eventualmente, podía terminar con el desenlace fatal de un femicidio.

A diferencia del derecho canónico que incluía entre sus causales de separación eclesiástica el adulterio de ambos cónyuges, en la legislación civil se privilegió un sesgo de género, en donde el adulterio femenino y no el masculino era contemplado como causal de divorcio. En el caso de los maridos, se consideraba causal el concubinato público y escandaloso, incluso acompañado del abandono o menosprecio de su esposa en el Código Civil de Honduras (1906). En el Código Civil de Nicaragua (1904 y 1931), la esposa tenía incluso que soportar y demostrar el concubinato del marido, quien lleve a la "concubina" a vivir a su casa o en otro sitio notorio, resultando una injuria grave para la mujer20.

A esto hay que agregar que, en los códigos penales, se consideraba un delito el adulterio femenino y el marido se salvaba de una pena de cárcel, en caso de que cometiera homicidio/feminicidio, cuando encontrara a su esposa teniendo relaciones sexuales con otra pareja. En efecto, en Costa Rica fue hasta en el Código Penal de 1941 que se eliminaron como delitos "contra la honestidad" el adulterio femenino y el concubinato escandaloso ${ }^{21}$.

El análisis de las causales de divorcio civil también revela una influencia importante del ideal del matrimonio afectuoso, armónico y por compañerismo, y un mayor énfasis en la regulación de la conducta del marido conforme al ideal de jefe de familia y de principal proveedor. Es decir, en cuanto a su deber de proveer económicamente las necesidades de la familia y tener una conducta honorable, para lo cual era fundamental no tener vicios como el alcoholismo, el

19 Código Civil de Costa Rica 1888 (Libro I, Arts. 80-82, 91-95, Art. 91, Inc. $5^{\circ}$ y 92) (causal mutuo consentimiento).

20 Código Civil de Honduras 1906 (Libro I, Arts. 167-168); Código Civil de la República de Nicaragua 1904 (Libro I, Arts. 94-95, 161-164, 174); Código Civil de la República de Nicaragua, $3^{a}$ ed. oficial, 1931, (Libro I, Art. 174).

21 En el Código Penal de la República de Costa Rica. Año de 1924 se consideraban delitos el adulterio femenino y el concubinato escandaloso (Arts. 292-299); sin embargo, fueron eliminados en el Código Penal de 1941 (Arts. 216-234). Para un análisis más detallado, véase: Rodríguez, 2006, 186-188. 
juego y los narcóticos, ni provocar escándalos públicos que atentaran contra la estabilidad y la honorabilidad de la familia (como por ejemplo el concubinato escandaloso). Esta tendencia se evidencia, en el hecho de que en los códigos civiles del siglo XIX y de las primeras décadas del siglo XX, se admitían como causales de divorcio: el adulterio de la mujer; que el marido le negara los alimentos a su mujer e hijos (aunque el derecho canónico no lo aceptaba); el exceso, la sevicia o injurias graves recíprocas y la condena de uno de los cónyuges a pena infamante ${ }^{22}$.

\section{Patria potestad compartida entre el padre y la madre}

En el marco de altas tasas de mortalidad durante el siglo XIX, la etapa de matrimonio se encontraba por lo general interrumpida por la muerte de uno de los cónyuges, y principalmente del esposo. Por lo tanto, se dio un predominio de las viudas sobre los viudos, y de acuerdo a Arrom, las mujeres tenían bastantes "probabilidades de ser viuda[s] durante la mitad de su vida adulta" (Arrom, 1988, 145).

De manera que, con la muerte del cónyuge, la viuda y sus hijos debían afrontar la situación de cómo subsistir y mantener el acceso a los bienes, así como el usufructo de estos. Aunque la manutención de la esposa e hijos se incluía dentro de la normativa, las posibles deudas y demandas podían implicar condiciones difíciles para la familia doliente. A esto hay que agregar que, en los primeros códigos civiles de El Salvador, Nicaragua y Costa Rica, a la madre no se le daba el derecho en primer lugar a ejercer la patria potestad una vez fallecido el esposo ${ }^{23}$.

En efecto, las primeras normativas indicaban que la patria potestad solo se adjudicaba al padre o a la madre en caso de que el marido lo autorizara, pero este también, en su condición de padre, podía escoger a otro hombre para ejercerla una vez que faltara; y, si ambos padres habían muerto y no se había elegido a un tutor se debía dar preferencia al abuelo paterno. A este respecto se indicaba en el Código Civil de Nicaragua de 1871, que:

Artículo 243. La Patria potestad es el conjunto de derechos que la ley da al padre legítimo sobre sus hijos no emancipados. -Estos derechos no pertenecen a la madre.

22 Código Civil de la República de Guatemala, 1926 (Libro I, Arts. 118, 148-150, 152-154); Código Civil de El Salvador, ed. 1904 (Libro I, Art. 98) (Súarez, 1949: 56-57); Código Civil de la República del Salvador 1912, $5^{a}$ ed. (Libro I, Tit. IV, Arts. 97-98, 117, 132, 144-145, 182-184); Código Civil de Honduras de 1880 (Libro I, Arts. 129, 143-150); Código Civil de Honduras de 1898 (Libro I, Arts. 33-34, 58, $75-$ 78); Código Civil 1906 (Libro I, Arts. 167-168); Código Civil de la República de Nicaragua 1904 (Libro I, Arts. 94-95, 161-164, 174). También, Deere y León, 2005: 40-41; Código Civil de la República de Nicaragua, $3^{a}$ ed. oficial, 1931 (Libro I, Art. 174); Código Civil de Costa Rica 1888 (Libro I, Arts. 80-82, 91-95); Código Civil de Panamá 1917, 1960: 10-11, (Libro I, Arts. 88, 91ª, 114 Inc. 11ª 119 123).

23 Código Civil El Salvador 1860 (Libro I, Art. 244); Código Civil Nicaragua 1871 (Libro I, Art. 243); Código General de Costa Rica 1841 (Libro I, Arts. 194-195, 199 y 208). 
Los hijos de cualquiera edad, no emancipados, se llaman hijos de la familia, y el padre, con relación a ellos, padre de familia ${ }^{24}$.

Sin embargo, se dieron importantes cambios graduales en el ejercicio de la patria potestad en los primeros códigos civiles de Honduras y Guatemala, al establecerse la patria potestad compartida entre el padre y la madre, y a falta del padre se le autorizaba a la madre a ejercer la tutela sobre sus hijos, con lo cual se reforzó la capacidad legal de las esposas ${ }^{25}$.

De acuerdo con el Cuadro 3, Guatemala (1877) fue el primer país de América Central en donde se estableció la normativa de la patria potestad compartida, seguido en la década de 1880 por Honduras, El Salvador y Costa Rica, y a inicios del siglo XX por Nicaragua y Panamá.

\begin{tabular}{|c|c|c|}
\hline \multicolumn{2}{|c|}{ CuAdro 3. PATRIA POTESTAd En AmÉRICA CENTRAL (SIGLOS XIX Y XX) } \\
\hline País & Patria potestad del padre $^{1}$ & Patria potestad compartida $^{2}$ \\
\hline Costa Rica & 1841 & 1888 \\
\hline El Salvador & 1860 & $1880 / 1902$ \\
\hline Nicaragua & 1871 & 1904 \\
\hline Guatemala & ----- & 1877 \\
\hline Honduras & ----- & 1880 \\
\hline Panamá & ----- & 1917 \\
\hline
\end{tabular}

Notas:

1. Patria potestad del padre: Código Civil El Salvador 1860 (Libro I, Art. 244); Código Civil Nicaragua 1871, (Libro I, Art. 243); Código General de Costa Rica 1841 (Libro I, Arts. 93, 188-190, 192, 194-195, 199 y 208).

2. Patria potestad compartida: Código Civil de Guatemala 1877 (Libro I, Arts. 285-286, 290); Código Civil de El Salvador 1860 ed. 1912 (Libro I, Arts. 252-256); Código Civil de Honduras 1880 (Libro I, Art. 272-273); Código Civil de Honduras 1898 (Libro I, Arts. 131-141); Código Civil de Nicaragua 1904 (Libro I, Arts. 244-249, 260-261); Código Civil de Costa Rica 1888 (Libro I, Arts. 129,132, 138-143); Código Civil de Panamá de 1917 (Libro I, Arts. 187-192).

Fuentes: María G. Leret de Matheus, La mujer: una incapaz como el demente y el niño. (Según las leyes latinoamericanas), México, Costa-Amic Editor, 1975, 51, 112, 131, 194 y 276; Carmen Diana Deere y Magdalena León. El liberalismo y los derechos de propiedad de las mujeres casadas en el siglo XIX en América Latina. En Magdalena León y Eugenia Rodríguez. (Eds.). ¿Ruptura de la inequidad? Propiedad y género en la América Latina del siglo XIX (Bogotá, Siglo del Hombre Editores, 2005), 40-41, 47-49, 71 y 92-103; Carmen Diana Deere y Magdalena León, Matrimonio y divorcio civil en América Latina durante el siglo XIX.En XI Cátedra Anual de Historia Ernesto Restrepo Tirado. (Ed.). Mujer, nación, identidad y ciudadanía: siglos XIX y XX (Bogotá, MinCultura Memorias, 2006), 78-101; Eugenia Rodríguez, Las esposas y sus derechos de acceso a la propiedad en Costa Rica durante el siglo XIX. En Magdalena León y Eugenia Rodríguez. (Eds.). ¿Ruptura de la inequidad? Propiedad y género en la América Latina del siglo XIX (Bogotá, Siglo del Hombre Editores, 2005a), 183-232.

24 Código Civil Nicaragua 1871 (Libro I, Art. 243). El subrayado es del original.

25 Código Civil Honduras 1880 (Libro I, Arts. 272-273); Código Civil Guatemala 1877 (Libro I, Arts. 285286, 290). 
De acuerdo con el Código Civil de Guatemala de 1877, se establecía la patria potestad y su ejercicio compartido por el padre y la madre, aunque solo el padre estaba autorizado para ejercerla en caso de que el hijo fuera mayor de 16 años o habilitado por la edad. A este respecto, el código guatemalteco determinaba que:

Artículo 285. Patria potestad es la autoridad que las leyes reconocen en los padres sobre la persona y bienes de sus hijos.

Artículo 286. Los hijos legítimos, legitimados, ilegítimos reconocidos y adoptivos, están sujetos a la autoridad del padre, y en su defecto a la de la madre [...].

290. Los derechos concedidos al padre [...] se extienden, en ausencia, inhabilidad o muerte suya a la madre, o a cualquiera otra persona a quien corresponda el cuidado personal del hijo, pero solo el padre podrá ejercerlos sobre el hijo mayor de diez y seis años o habilitado de edad ${ }^{26}$.

La introducción de la patria potestad constituye una importante innovación que generó debates relevantes. A este respecto es ilustrativo el artículo de Francisco V. Sáenz, quien consideraba que los miembros de la Comisión Codificadora del Código Civil de Costa Rica (1888), habían implementado dicha normativa con el fin de brindarle a la madre un derecho legítimo, acorde con la civilización y las corrientes progresistas, y con:

Las exigencias de la sociedad en que vivimos, que no puede menos que mirar con desprecio las instituciones antiguas que en tan poca estima tenían a la mujer [...]. Que en el tiempo en que fue emitido nuestro Código General se dejara sin incluir tal derecho en el cuerpo de sus disposiciones, no es de extrañar. Acostumbrados, como lo estábamos, a regirnos durante mucho tiempo por las leyes españolas tan parcas en la parte referente a derechos mujeriles, no es raro, y aun parece natural, que habiéndose promulgado aquel Código pocos años después de nuestra independencia política, cuando aún estaban profundamente arraigadas en nuestros hombres de estado tradicionales preocupaciones, no se concediera a las madres un derecho tan legítimo27.

Sin embargo, el ejercicio real de la patria potestad por parte de las mujeres se encontraba sometido a ciertas limitaciones. Por ejemplo, en el caso mexicano Carmen Ramos señala la existencia de una ley que habilitaba al esposo a que nombrara consejeros en su testamento, a los cuales la madre debía obedecer, o en caso contrario ella podía perder la patria potestad. En caso de divorcio, la patria potestad quedaba en manos del cónyuge inocente, o sea que el culpable la perdía; sin embargo, en caso de culpabilidad de la madre, esta podría ejercerla sobre sus hijos menores de cinco años (Ramos 2005, 127-139).

A esto hay que agregar, que en los códigos civiles centroamericanos la legislación contemplaba que si la madre o la viuda, había sido sentenciada por causa criminal, o se volvía a casar perdía la patria potestad y la administración

26 Código Civil Guatemala 1877 (Libro I, Arts. 285-286, 290).

27 Francisco V. Sáenz, El Foro, Tomo IV, No. 126, 26/3/1890, 339-340. 
de los bienes del hijo menor ${ }^{28}$. Por lo tanto, aún después de haber fallecido el padre este mantenía el control sobre los bienes de los hijos al nombrar consejeros por su línea (abuelo por línea paterna), con lo cual se buscaba garantizar que las propiedades y bienes fueran transmitidos preferentemente por vía paterna. De esta manera, podría afirmarse que esta es otra práctica que explica en parte por qué los hombres podían verse más beneficiados en cuanto al control y acceso a la propiedad en comparación con las mujeres.

No obstante, debemos tener en consideración que este cambio en cuanto al ejercicio de la patria potestad por parte de las mujeres, aunque limitado y en un contexto que favorecía el ejercicio de la autoridad del hombre como cabeza de familia, tendía a fortalecer el papel de las mujeres en cuanto al ejercicio de su autoridad sobre sus hijos y a redefinir las relaciones de poder en la pareja. Este cambio puede explicarse en parte, por el auge del ideal de la maternidad de fines del siglo XIX, el cual exaltaba las funciones tradicionales de las mujeres como esposas y madres garantes de la crianza de los hijos conforme a los patrones liberales del orden, el progreso y la civilización (Rodríguez 1998, 33-42; Rodríguez 1999, 85-122; Mora 2003, 181-199).

\section{Epílogo: entre cambios progresivos y regresivos}

La evidencia precedente ha demostrado que la implementación de las reformas liberales entre el siglo XIX e inicios del siglo XX, no implicaron rupturas drásticas con respecto a la época colonial, sino que introdujeron cambios graduales los cuales contribuyeron a redefinir y secularizar las funciones de la familia y el matrimonio, las relaciones de género y los derechos de las mujeres centroamericanas. Además, la introducción de dichas reformas implicaron la redefinición legal y la secularización del matrimonio como "contrato soluble" versus el matrimonio católico como un "contrato indisoluble".

Estas reformas, sin duda, marcaron un hito porque debilitaron tanto como fortalecieron los derechos civiles de las mujeres -en particular de las mujeres casadas-, y más que "modernizar", contribuyeron a la vez a redefinir las relaciones y las identidades de género, y a reforzarlas bajo los mandatos del "orden" patriarcal y heterosexual. Es decir, la construcción identitaria de la mujer como esposa y madre recluida en el ámbito doméstico, sumisa, dependiente, obediente y dedicada a la crianza y a la educación de los hijos. Además, la construcción identitaria del hombre como jefe del hogar y principal proveedor, trabajador y sin vicios.

28 Código Civil de Guatemala 1877 (Libro I, Arts. 285-286, 290); Código Civil de El Salvador 1860 ed. 1912 (Libro I, Arts. 252-256); Código Civil de Honduras 1880 (Libro I, Arts. 275-276); Código Civil de Honduras 1898 (Libro I, Arts. 145-146); Código Civil de Honduras 1906 (Libro I, Arts. 242); Código Civil 129, 132, 138-143); Código Civil de Panamá 1917 (Libro I, Arts. 187-192). 
Las reformas liberales, durante el siglo XIX e inicios del siglo XX, se vieron acompañadas del desarrollo e institucionalización de diversas instituciones represivas, punitivas de la moral sexual y doméstica, lo cual se expresó en particular en el control, la regulación y criminilización de los cuerpos y la sexualidad de las mujeres, y la represión de aquellas conductas que eran consideradas transgresoras del "orden" patriarcal y heterosexual. En este sentido, y en relación con las mujeres casadas, destaca la introducción de las siguientes reformas que redefinieron el control y la regulación del cuerpo, la sexualidad y la maternidad: a) el matrimonio como contrato civil; b) la eliminación de la potestad marital; c) la regulación y control de la sexualidad y de la maternidad; y d) el ejercicio de la patria potestad compartida.

Este artículo nos permite dar otras miradas al papel de las legislaciones en la construcción y transformación de las identidades de género, y a la vez nos permitirá contextualizar y comprender mejor los procesos posteriores de movilización, organización y luchas de las mujeres por democratizar la región centroamericana, y también por ampliar sus derechos durante los siglos XX y XXI.

Como este trabajo forma parte de una investigación más amplia sobre los derechos civiles de las mujeres centroamericanas, es también un punto de partida para la realización de investigaciones futuras más profundas, que nos permitan comprender mejor el impacto que tuvieron dichas reformas en las identidades y las relaciones de género.

\section{Fuentes Primarias}

\section{Costa Rica:}

Costa Rica. (1858). Código General de Costa Rica (1841). Nueva York: Imprenta de Wynkoop, Hallenbeck y Thomas.

Costa Rica. (1910). Código Civil 1888, $2^{a}$ ed. San José: Tipografía Nacional.

Costa Rica. (1924). Código Penal de la República de Costa Rica. Año de 1924. San José: Imprenta María V. De Lines.

Costa Rica. (30 de agosto de 1941). Código Penal de 1941. En Alcance La Gaceta, 192. San José: Imprenta Nacional.

Costa Rica. (1974). Código de Familia. San José: Tipografía Nacional.

Costa Rica. (12 de junio de 1884). El Foro, 25, 8.

Costa Rica. (20 de abril de 1886). El Foro, 74-76, 206.

Orozco, Rafael. (6 de abril de 1884). Decreto de aprobación del matrimonio civil. El Foro, 24, 6.

Sáenz, Francisco V. (26 de marzo de 1890). El Foro, 126, 339-340. 


\section{El Salvador:}

El Salvador. (1860). Código Civil de la República del Salvador en Centroamérica. Nueva York: Imprenta de Eduardo C. Jenkins.

El Salvador. (1893). Código Civil de la República del Salvador. Tercera edición en la que se han intercalado las reformas posteriores hasta el año de 1890. San Salvador: Tipografía "La Luz".

El Salvador. (1912). Código Civil de la República del Salvador. Quinta edición en la que se han intercalado todas las reformas posteriores hasta el año de mil novecientos doce. Editores y propietarios Dutriz Hermanos. San Salvador: Tipografía "La Unión".

El Salvador. (1960). Código Civil de la República del Salvador en Centroamérica. (Estudios y conferencias sobre el Código Civil de 1860), $2^{\mathrm{a}}$ ed. San Salvador: Editorial Universitaria "José B. Cisneros", 13 de julio.

Guzmán, Mauricio. (1959). Código Civil de El Salvador. Estudio preliminar de D. Mauricio Guzmán Doctor en Derecho. Madrid: Instituto de Cultura Hispánica.

Lindo, Hugo. (1959). El divorcio en El Salvador. Historia legislativa, jurisprudencia, anotaciones críticas ( $2^{\mathrm{a}}$ ed). Colección Tesis Escogidas, Vol. 2. San Salvador: Editorial Universitaria "José B. Cisneros".

Súarez, Berlamino. (1949). El Código Civil del año de 1860 con sus modificaciones 1860-1948. Tomo I. San Salvador: Imprenta La Idea.

\section{Guatemala:}

Guatemala. (1877). Código Civil de la República de Guatemala, 1877. Ciudad de Guatemala: Imprenta El Progreso.

Guatemala. (1881). Recopilación de las leyes emitidas por el gobierno democrático de la República de Guatemala desde el 3 de junio de 1871 hasta 30 junio 1881. Tomo I. Ciudad de Guatemala: Tipografía El Progreso.

Guatemala. (1882). Ley de reforma al Código Civil 1882. Justo Rufino Barrios. Guatemala: Tipografía Nacional.

Guatemala. (1883). Recopilación de las leyes emitidas por el gobierno democrático de la República de Guatemala desde el 1 de julio de 1881 hasta 30 junio 1883. Tomo III. Ciudad de Guatemala: Tipografía El Progreso.

Guatemala. (1883). Iniciativa de algunos Diputados a la Asamblea Nacional Legislativa sobre el Divorcio. Guatemala: Oficina Tipográfica El Progreso.

Guatemala. (1923). Leyes que reglamentan la celebración del matrimonio civil. Ciudad de Guatemala: Tipografía Nacional. 
Guatemala. (1927). Código Civil de la República de Guatemala, 1926. Ciudad de Guatemala: Tipografía Nacional.

Guatemala. (1937). Código Civil de la República de Guatemala, 1937. Guatemala: Tipografía Nacional.

Cruz, Fernando. (1882). Instituciones de derecho civil patrio, escritas por Fernando Cruz. Tomo 1. Guatemala: Tipografía el Progreso.

Pineda de Mont, Manuel. (1872). Recopilación de las leyes de la República de Guatemala compuesta y arreglada por Don Manuel Pineda de Mont. Tomo 3. Guatemala: Imprenta de La Paz.

\section{Honduras:}

Honduras. (1881). Lei de Matrimonio Civil de la República de Honduras emitida el 15 de julio de 1880. Marco Aurelio Soto, Presidente Constitucional de la República de Honduras, decreto del 25 de octubre de 1880, Lei de Matrimonio Civil. Tegucigalpa: Tipografía Nacional.

Honduras. (1880). Código Civil de la República de Honduras 1880. Tegucigalpa: Tipografía Nacional.

Honduras. (1898). Código Civil de 1898. Tegucigalpa: Tipografía Nacional.

Honduras. (1906). Código Civil 1906. Tegucigalpa: Tipografía Nacional.

Honduras. (1997). Código Civil 1906. Tegucigalpa: Scancolor.

\section{Nicaragua:}

Nicaragua. (1871). Código Civil de la República de Nicaragua aprobado 25 enero 1867. Managua: Imprenta de El Centro-Americano.

Nicaragua. (1903). Código Civil de la República de Nicaragua elaborado de orden del Señor Presidente General Don J. Santos Zelaya y su Ministro de Justicia Don Fernando Abaunza, por la Comisión Oficial de Códigos compuesta de los Abogados Bruno H. Buitrago, José Francisco Aguilar y Francisco Paniagua Prado. Managua: Tipografía Nacional (vigente a partir de 1904).

Nicaragua. (1931). Código Civil de la República de Nicaragua. Revisado definitivamente por la Comisión Legislativa compuesta de los Diputados Doctor don Leonardo Rodríguez y don Santiago López y de los Abogados Bruno H. Buitrago, J. F. Aguilar y F. Paniagua Prado. Tercera Edición Oficial. Anotada y concordada por los doctores Carlos A. Morales, Joaquín Cuadra Zavala y Mariano Argüello ( $3^{\mathrm{a}}$ ed. oficial). Managua: Casa Editorial Carlos Heuberger y Co.

Bonilla, T. G. (1894). El matrimonio en el Código de la Familia y sus efectos civiles. Managua: Tipografía Nacional. 


\section{Panamá:}

Panamá. (1960). Código Civil de la República de Panamá. Edición conmemorativa del XXV aniversario. Panamá: Universidad de Panamá29.

Correa, Alfonso. (1927). Código Civil de la República de Panamá. Anotaciones. Panamá: Imprenta Nacional.

Fábrega, Ramón E. (1969). Constituciones de la República de Panamá de (19041941-1946). Edición preparada por Ramón E. Fábrega F. Panamá: s.ed.

\section{Bibliografía}

Abrams, Lynn. (1999). Crime Against Marriage? Wife-beating, Divorce and the Law in Nineteenth-Century Hamburg. En Arnot, Margaret L. y Usborne, Cornelie. (Eds.). Gender and Crime in Modern Europe. London: UCL Press \& Taylor Group, 118-136.

Aguilar, Ana Leticia. (Ed.). (1997). Movimiento de Mujeres en Centroamérica. Managua: Programa Regional La Corriente.

Arrom, Silvia. (1985). Changes in Mexican Family Law in the Nineteenth Century: The Civil Codes of 1870 and 1884. Journal of Family History, 10(3), 305-317.

Arrom, Silvia. (1988). Las mujeres en la ciudad de México, 1790-1857. México: Siglo XXI Editores.

Beeche, Héctor y Fournier, Fabio. (1962). Código Civil de Costa Rica. Estudio preliminar, Compendio y Concordancias a cargo de los Licenciados Héctor Beeche Luján y Fabio Fournier Jiménez. Madrid, España: Instituto de Cultura Hispánica.

Bonilla, T. G. (1894). El matrimonio en el Código de la Familia y sus efectos civiles. Managua: Tipografía Nacional.

Brenes, Alberto. (1974). Tratado de las personas. Notas y comentario de Eladio Vargas. San José: Editorial Costa Rica.

Deere, Carmen Diana \& León, Magdalena. (2000). Género, propiedad y empoderamiento: tierra, Estado y mercado en América Latina. Bogotá: Tercer Mundo Editores.

Deere, Carmen Diana \& León, Magdalena. (2005). El liberalismo y los derechos de propiedad de las mujeres casadas en el siglo XIX en América Latina. En León, Magdalena y Rodríguez, Eugenia. (Eds.). ¿Ruptura de la inequidad?

29 Esta edición es una versión revisada del Código Civil de 1917, el cual estuvo vigente a partir de noviembre de 1917. Antes de este código estuvo vigente el Código Civil Colombiano (Código Civil de la República de Panamá, 1960, 1). 
Propiedad y género en la América Latina del siglo XIX. Bogotá: Siglo del Hombre Editores.

Deere, Carmen Diana \& León, Magdalena. (2006). Matrimonio y divorcio civil en América Latina durante el siglo XIX. En XI Cátedra Anual de Historia Ernesto Restrepo Tirado. (Ed.). Mujer, nación, identidad y ciudadanía: siglos XIX y $X X$. Bogotá, MinCultura Memorias.

Donoso, Justo. (1844). Manual del Párroco Americano. Santiago: Imprenta del Progreso.

Facio, Alda. (1989). La igualdad entre hombres y mujeres y las relaciones familiares en la legislación centroamericana. Estudios Sociales Centroamericanos, 50(2).

Foucault, Michel. (1989). Vigilar y castigar: nacimiento de la prisión. México: Siglo XXI Editores.

Foucault. Michel. (2012). Historia de la sexualidad. I, la voluntad de saber. Madrid: Siglo XXI Editores.

García, Ana Isabel. (1999). Mujeres, participación política y ciudadanía. Un ejemplo de la aplicabilidad del sistema de cuotas: Costa Rica. En García, Ana Isabel. (Ed.). La situación de las mujeres en Centroamérica: una evaluación en el umbral del siglo XXI. San José: Fundación Género y Sociedad, Diálogo Interamericano.

García, Ana Lidia. (2006). El fracaso del amor. Género e individualismo en el siglo XIX mexicano. Distrito Federal: El Colegio de México-Universidad Autónoma del Estado de México.

INAMU. (2009). Los derechos humanos políticos de las mujeres: normativa, doctrina y jurisprudencia. Compendio 2006. San José: Instituto Nacional de las Mujeres, Colección Legislación, No.16.

Lamas, Marta. (1996). Usos, dificultades y posibilidades de la categoría 'género'. En Lamas, Marta. (Comp.). El género: la construcción cultural de la diferencia sexual. México: Grupo Editorial Miguel Angel Porrúa.

Lavrin, Asunción. (1995). Women, Feminism, and Social Change in Argentina, Chile and Uruguay, 1890-1940. Lincoln and London: University of Nebraska Press.

Lavrin, Asunción. (1997). Género e Historia: Una conjunción a finales del siglo XX. En Memorias $49^{\circ}$ Congreso Internacional de Americanistas, Colección 49 ICA, No. 1. Quito: Ediciones Abya-Yala.

Leret, María G. (1975). La mujer: una incapaz como el demente y el niño. (Según las leyes latinoamericanas). Distrito Federal: B. Costa-Amic Editor. 
Mahoney, James. (2002). Los patrones de dependencia en los cambios de régimen: América Central en perspectiva comparada. Araucaria. Revista Iberoamericana de Filosofía Política y Humanidades, 4(7), 133-166.

Marín, Juan José. (2005). Prostitución y explotación sexual infantil y juvenil en Costa Rica (1860-1949). En Rodríguez, Eugenia. (Ed.). Abuso sexual y prostitución infantil y juvenil en Costa Rica durante los siglos XIX y XX. San José: Plumsock Mesoamerican Studies, 127-161.

Marín, Juan José. (2007). Prostitución, honor y cambio cultural en la provincia de San José de Costa Rica: 1860-1949. San José: Editorial Universidad de Costa Rica.

Mendoza Orantes, Ricardo. (Ed.). (1994). República de El Salvador Código de Familia y Reformas al Código Civil. San Salvador: s.ed.

Miguelez Lorenzo, Alonso, Sabino y Cabreros, Marcelino. (1947). Código de Derecho Canónico y Legislación Complementaria. Texto Latino y Versión Castellana, $2^{a}$ ed. Ampliada. Madrid: La Editorial Católica.

Molina, Iván y Palmer, Steven. (1998). Historia de Costa Rica. Breve, actualizada y con ilustraciones. San José: Editorial Universidad de Costa Rica.

Molina, Iván y Palmer, Steven. (2003). Educando a Costa Rica. Alfabetización popular, formación docente y género (1880-1950). San José: Editorial Universidad Estatal a Distancia.

Molina, Iván y Palmer, Steven. (2003). Desertores e invasoras. La feminización de la ocupación docente en Costa Rica a comienzos del siglo XX. En Molina, Iván y Palmer, Steven. Educando a Costa Rica. Alfabetización popular, formación docente y género. San José: Editorial Universidad Estatal a Distancia.

Molina, Iván y Palmer, Steven. (2004). Popular Literacy in a Tropical Democracy: Costa Rica 1850-1950. Past and Present, 184(3), 169-207.

Mora, Virginia. (2003). Rompiendo mitos y forjando historia. Mujeres urbanas y relaciones de género en el San José de los años veinte. Alajuela: Museo Histórico Cultural Juan Santamaría.

Muñoz, lleana. (2002). Educación y régimen municipal en Costa Rica (18211882). San José: Editorial Universidad de Costa Rica.

Palmer, Steven. (1999). Adiós Laissez-faire: la política social en Costa Rica (1880-1940). Revista de Historia de América, 124(1), 99-117.

Palmer, Steven y Rojas, Gladys. (2003). Educando a las señoritas: formación docente, movilidad social y nacimiento del feminismo en Costa Rica (1885-1925). En Molina, Iván y Palmer, Steven. Educando a Costa Rica. 
Alfabetización popular, formación docente y género. San José: Editorial Universidad Estatal a Distancia.

Pérez, Héctor. (1989). Breve historia de Centroamérica, $2^{a}$ ed. México: Alianza Editorial Mexicana.

Ramos, Carmen. (2005). Entre la ley y el cariño. Normatividad jurídica y disputas familiares sobre la patria potestad en México (1873-1896). En Potthast, Bárbara y Carreras, Sandra. (Eds.). Entre la familia, la sociedad y el Estado. Niños y jóvenes en América Latina (siglos XIX-XX). Madrid: Iberoamericana, Vervuert.

Rodríguez, Eugenia. (1994). 'Tiyita bea lo que me han hecho'. Estupro e incesto en Costa Rica (1800-1850). En Molina, Iván y Palmer, Steven. (Eds.). El paso del cometa. Estado, políticas sociales y culturas populares en Costa Rica, 1800-1950. San José: Editorial Porvenir, Plumsock Mesoamerican Studies.

Rodríguez, Eugenia. (1998). Inventando el Día de la Madre en Costa Rica (19101932). Revista Reflexiones, (75), 33-42.

Rodríguez, Eugenia. (1999). "Nicolasa, ¿Hábrase visto cosa igual?..." Los discursos sobre la participación de las mujeres en la política en Costa Rica (1900-1950). Revista Parlamentaria, 7(1), 85-122.

Rodríguez, Eugenia. (2000). Hijas, novias y esposas. Familia, matrimonio y violencia domestica en el Valle Central de Costa Rica (1750-1850). Heredia: Editorial de la Universidad Nacional-Plumsock Mesoamerican Studies.

Rodríguez, Eugenia. (2001). Construyendo la Identidad Nacional. Redefiniendo la Familia y las Relaciones de Género en Costa Rica (1890-1950). Instituto Panamericano de Geografía e Historia. (Ed.). Memoria del IV Simposio Panamericano de Historia. México: IPGH, 211-255.

Rodríguez, Eugenia. (2002). Conclusión. Género e historia en América Central: un balance (1957-2001). En Rodríguez, Eugenia. (Ed.). Mujeres, Género e Historia en América Central (1700-2000). San José: UNIFEM Oficina Regional de México, Centroamérica, Cuba y República Dominicana-Plumsock Mesoamerican Studies.

Rodríguez, Eugenia. (2005a). Women's History and Gender History in Central America: An Introductory Balance. En The International Federation for Research in Women's History (IFRW), “Women's History Revisited: Historiographical Reflections on Women and Gender in a Global Context", 20 ${ }^{\text {th }}$ International Congress on Historical Sciences. Sydney, Australia: University 
of New South Wales, 8-9 July. Recuperado de www.historians.ie/women/ Art.E.Rodriguez.IFRW.Sydney.pdf

Rodríguez, Eugenia. (2005b). Las esposas y sus derechos de acceso a la propiedad en Costa Rica durante el siglo XIX. En León, Magdalena y Rodríguez, Eugenia. (Eds.). ¿Ruptura de la inequidad? Propiedad y género en la América Latina del siglo XIX. Bogotá: Siglo del Hombre Editores, 183-232.

Rodríguez, Eugenia. (2005c). 'Víctimas inocentes/amenazas corruptoras'. Niñez, 'invención' del crimen juvenil y abuso sexual en Costa Rica (1800-1850 y 1900-1950). En Rodríguez, Eugenia. (Ed.). Abuso Sexual y Prostitución Infantil y Juvenil en Costa Rica: Rompiendo con Dos Siglos de Mitos. San José: Plumsock Mesoamerican Studies, 57-94.

Rodríguez, Eugenia. (2006). Divorcio y violencia de pareja en Costa Rica (18001950). Heredia: Editorial Universidad Nacional.

Rodríguez, Eugenia. (2008). Ciudadanía y derechos civiles y políticos de las mujeres en Costa Rica (siglos XIX y XX). En Santana, Adalberto. (Ed.). Costa Rica Contemporánea. Distrito Federal: Centro de Investigaciones sobre América Latina y el Caribe, Universidad Nacional Autónoma de México.

Rodríguez, Eugenia. (2014). Historia de las mujeres y de género en Costa Rica: avances y desafíos. En Díaz, David; Molina, Iván y Viales, Ronny. (Eds.). La historiografía costarricense en la primera década del siglo XXI: tendencias, avances e innovaciones. San José: Editorial Universidad de Costa Rica.

Salvatierra, Leda; Suñol, Amira y Trejos, Ana María. (1978-1980). Realidad jurídico-social de la mujer costarricense. San José: Comisión Interamericana de Mujeres.

Scott, Joan W. (1988). Gender and the Politics of History. New York: Columbia University Press.

Scott, Joan W. (Ed.). (1996). Feminism and History. Oxford: Oxford University Press.

Trejos, Gerardo y Ramírez, Marina. (1999). Derecho de familia costarricense. Tomo I. San José: Editorial Juricentro.

Vargas, Claudio. (1991). El liberalismo, la Iglesia y el Estado en Costa Rica. San José: Ediciones Guayacán.

Vázquez, Francisco. (2013). Hipótesis represiva e hipótesis productiva. El contexto historiográfico de La voluntad de saber. Del Val, María Isabel y Gallego, Henar. (Eds.). Las huellas de Foucault en la historiografía. Barcelona: Icaria Editorial, Colección Historia y Feminismo. 